\title{
Nonfatal Bicycle Accident Risk After an Evening of Alcohol Consumption
}

\author{
Joris C. Verster ${ }^{*}$, Jessica van Herwijnen, Edmund R. Volkerts and Berend Olivier \\ Utrecht Institute for Pharmaceutical Sciences, Department of Psychopharmacology, Utrecht University, PO BOX \\ 80082, 3508 TB, Utrecht, The Netherlands
}

\begin{abstract}
Introduction: After an evening of alcohol consumption, blood alcohol concentration (BAC) may reach intoxication levels above legal limits for operating a car or bicycle. In the Netherlands, legal limits for participating in traffic are $0.05 \%$ for experienced drivers and $0.02 \%$ for novice drivers. The purpose of this study was to determine bicycle accident risk of Dutch students after an evening of alcohol consumption.

Methods: A survey was conducted among 800 University and college students in Utrecht, The Netherlands. The survey included retrospective questions concerning alcohol consumption on a typical night out and the start and end time of consumption. For those who travel home by bicycle, BAC was computed and relative risk of having a bicycle accident. Finally, they reported the likelihood $(0-100 \%)$ that they would consume less alcohol when police controls for drunk bicycling were comparable to those for car drivers (with a similar chance of getting caught and a similar fine for driving when drunk).

Results: 761 surveys $(95.3 \%)$ were eligible for statistical evaluation. 690 students reported going to the pub for a night out, on average 1.6 times per week. 445 students $(64.5 \%)$ reported traveling home by bicycle often or always. They reported drinking an average of 6.8 alcoholic drinks (Standardized drinks contain 12 gram alcohol) and their mean (SD) BAC when traveling home was $0.95(0.9) \%$. The percentage of past year accidents or injury among those traveling home by bicycle often or always but consumed no alcohol $(\mathrm{BAC}=0 \%)$ was $2 \%$. Alcohol consumption significantly increased the risk of bicycle accidents (Odds ratio: 6.8). Odds ratio of having a bicycle accident increased exponentially when having a higher BAC: $2.5(\mathrm{BAC}=0-0.2 \%), 6.8(\mathrm{BAC}=0.2-0.5 \%), 6.0(\mathrm{BAC}=0.5-1.0 \%), 16.4(\mathrm{BAC}=1.0-1.5 \%)$ and $11.1(\mathrm{BAC}$ $>1.5 \%)$. Logistic regression analysis revealed a significant $(\mathrm{p}<0.006)$ relationship between alcohol consumption and the risk of a bicycle accident. Students who travel home by bicycle report that there is a $41.9 \%$ chance that they will consume less alcohol on a night out when police controls for driving drunk are the same as for car drivers. This was not related to BAC levels.

Conclusions: On average, students have blood alcohol concentrations that are five-fold higher than allowed to participate in traffic. Nevertheless, most of them travel home by bicycle after an evening of alcohol consumption. This is of great concern, since the risk of having a bicycle accident increases with higher BAC levels.
\end{abstract}

Keywords: Alcohol, bicycle, accident, injury.

\section{INTRODUCTION}

The risk of accident related injury when bicycling is much higher than when driving a car. In the UK, over 16.000 bicyclists are injured in reported traffic accidents [1]. In the USA, bicycle accidents cause about 1000 deaths yearly and 550.000 emergency department visits [2]. Intoxicated injured bicyclers have longer stays in the hospital that injured bicyclers that have not been drinking. The latter is expressed in a 6 tot 7-fold increase in hospital costs [3]. Since it is estimated that $60-90 \%$ of bicycle accidents are not reported this number significantly underestimates the real number of yearly accidents [4].

In the Netherlands, 151 bicycle deaths and 2186 bicycle accidents were reported in 2005 [5]. These numbers are very low taking into account the estimated 18 million bicycles

*Address correspondence to this author at the Utrecht University, Utrecht Institute for Pharmaceutical Sciences, Faculty of Science, Section Psychopharmacology, PO Box 80082, 3508 TB Utrecht, The Netherlands; Tel: +31 30253 6909; Fax: +31 30253 7900; E-mail: j.c.verster@uu.nl among 16 million inhabitants. On average, in 2007 the Dutch cycled $909 \mathrm{~km}$ per person. Both in cycling ownership and kilometers driven, the Netherlands has an unmet strong cycling culture. As a comparison, cycling ownership in the Netherlands is 2 to 3 times more common when compared to the UK and USA [6]. Contrary to popular belief, if more people ride a bicycle it is less likely that they get involved in traffic accidents. In fact, if the numbers of bicyclists are doubled, the percentage of bicycle accidents with cars will reduce by $34 \%$ [7]. The most likely reason for this is that bicycles among the traffic scene make motorists adjust their driving behavior, because they expect more bicycles once they have seen one.

Deadly accidents between two cyclists are rare. Most fatal bicycle accidents are caused by head injury involved in traffic accidents with motor vehicles $[8,9]$. However, it has been estimated that up to $50 \%$ of intoxicated bicycle riders ${ }^{1}$ cause the accident themselves and are involved in single-

\footnotetext{
${ }^{1}$ The term "intoxicated" is used to indicate that bicycle riders were under the influence of alcohol.
} 
vehicle accidents; i.e. falls [10-12]. Accidents and injury in intoxicated bicyclers occurred significantly more often at night, when returning from the pub $[13,14]$. Correspondingly, the highest incidence of accidents was reported on Tuesdays and Saturdays in those aged 17 to 24 , the two most popular days of the week to spend an evening in the pub [10].

Unfortunately, experimental research on cycling when intoxicated is scarce. One of these studies showed that when maneuvering on a test circuit bicycling was impaired at blood alcohol concentrations of $1.5 \%$. Relative to a sober drive, bicyclists made significantly more mistakes (falling or hitting a cone) on circuits driving between cones [15]. A more recent study showed that bicycle riding in the laboratory significantly worsened in a dose dependent manner after administration of alcohol [16].

Studies comparing intoxicated with sober cyclists show that those who were injured had higher blood alcohol concentrations than allowed to participate in traffic. For example, Kurzthaler and colleagues reported that $29.4 \%$ of Austrian cyclist who reported at emergency departments after having an accident consumed alcohol [17]. They had a mean BAC of 0.17 percent. In other countries such as Sweden [11], Australia [8] and the USA [18-22] reported percentages of injured intoxicated bicyclists range from $20 \%$ to $65 \%$.

$\mathrm{Li}$ and colleagues used a matched case-control design to assess the relative risk of fatal or serious injury in intoxicated bicyclers $(\mathrm{N}=102)$ compared to those of control subjects $(\mathrm{N}=285)$ [16]. The injured bicyclists were examined at the hospital (between 1985 and 1993) whereas the controls - who did not have an accident - were stopped along the road and a breath alcohol test was obtained. They found that the relative risk of becoming injured with a BAC greater than $0.2 \%$ $(\mathrm{RR}=5.6$; 95\%CI: 2.2-14.0) was significantly elevated when compared to sober cyclists and was even much higher for bicyclists with a BAC greater than $0.8 \%(\mathrm{RR}=20.2$; 95\%CI: 4.296.3). Unfortunately, this approach prevented to have a closer look at the dose-response relationship between BAC and the risk of bicycle accidents.

Two decades ago, Olkkonen and Honkanen examined the relationship between non-fatal bicycle accidents and alcohol consumption [23]. They reported that BACs ranging from $0.05 \%$ to $0.09 \%$ correspond to a two-fold increase of non-fatal bicycle injury. Relative to sober bicyclists, BACs greater than $0.10 \%$ were associated with a ten-fold increase in injury risk.

In this survey we addressed the following three questions about alcohol use and riding a bicycle:

1. What is the average BAC when returning home after spending an evening in the pub?

2. Did students who travel home by bicycle had accidents or not and is there a relationship with their blood alcohol concentration?

3. Will effective police controls cause bicyclers to consume less alcohol?

\section{METHODS}

\section{Survey}

A survey was conducted among 800 University and college students in Utrecht, The Netherlands. To establish a reflection of the general student population of Utrecht, students were approached at various locations such as colleges, campuses, fraternities and libraries. A survey team recruited the students. Students who agreed to participate $(\mathrm{N}=800)$ completed the survey at the location of recruitment. No recruitment rate was recorded, but the vast majority of students was willing to participate. No ethical approval was needed to conduct this anonymous survey. Participants were not compensated for completing the survey.

Students were asked the number of alcoholic drinks they consume on a typical night out. The number of weekly nights out was also recorded. Gender, body weight and start and stop time of drinking were asked in order to calculate the BAC estimate when returning home.

Mode of transportation when returning home was recorded and included walking, bicycling, car driving and public transport. Subjects could indicate whether they used this mode of transportation 'never', sometimes', 'now and then', 'often' or 'always'. We grouped responses into two categories: never/sometimes, often/always. The number of accidents during the past year were recorded and categorized as "falls with injury", "falls without injury", or "falls with injury requiring hospital treatment".

Finally, they reported the likelihood $(0-100 \%)$ that they would consume less alcohol when police controls for drunk bicycling were comparable to those for car drivers (with a similar chance of getting caught and a similar fine for driving when drunk).

\section{Statistical Analysis}

Mean and Standard Deviation (SD) and 95\% Confidence Interval $(95 \% \mathrm{CI})$ were computed for all variables. Given that retrospective reporting of numbers of alcoholic drinks may be biased, different BAC range groups were composed instead of using individually estimated BAC values: (1) $\mathrm{BAC}=0,(2) 0<\mathrm{BAC}<0.2$, (3) $0.21<\mathrm{BAC}<0.5$, (4) 0.51 $<\mathrm{BAC}<1.0$, (5) $1.0<\mathrm{BAC}<1.5$, and (6) $\mathrm{BAC}>1.5$.

A non-response to a particular question was treated as missing for all analyses using that variable.

\section{Calculation of the BAC Estimate}

The modified Widmark equation [24] was used to compute BAC estimates. The modified Widmark equation takes into account the number of alcoholic drinks, relative body water volume, weight, gender, and breakdown time of alcohol. The number of alcoholic drinks is expressed in grams of pure alcohol. In The Netherlands, each alcoholic drink contains a standardized amount of $12 \mathrm{~g}$ pure alcohol.

\section{Calculation of the Alcohol-Related Accident Risk}

For each BAC group, the relative risk of having had a bicycle accident during the past year was estimated by computed odds ratios. The odds ratios are relative accident risks of the different BAC groups compared to the accident risk of the group of sober cyclists $(\mathrm{BAC}=0)$ group (their risk is set to 1). Odds ratios greater than 1 indicate an increase in accident risk due to alcohol.

The risk of bicycle accidents in relation to alcohol consumption was also estimated through logistic regression. 


\section{Widmark Equation}

$$
\text { BAC }=\quad \begin{aligned}
& \text { A } \\
& \hdashline \mathbf{S}+(\mathbf{U} \times \mathbf{G})
\end{aligned}
$$

BAC is the blood alcohol concentration

$\mathbf{A}$ is the amount of pure alcohol that has been consumed (g)

$\mathbf{S}$ is the proportion of water in the body $(1 / \mathrm{kg})$, set at 17.45 for men and at 18.075 for women.

$\mathbf{G}$ is the total body weight of the drinker $(\mathrm{kg})$

$\mathbf{U}$ is a factor that correction factor for men (0.4786) and women $(0.3186)$

B is the breakdown speed of alcohol $(\mathrm{g} / \mathrm{l})$, set at 0.15

$\mathbf{t}$ is the time after consuming the first drink (hours)

$\mathbf{T}$ is the absorption time, set at 0.5 hours

Note: it must be acknowledged that this formula gives an estimate of the BAC level when returning home. Alcohol absorption and breakdown may differ significantly among individuals and depends on various factors such as drinking speed and having had a meal or not.

\section{Effectiveness of Police Controls}

The likelihood of drinking less (\%) when police controls are established to check BAC levels of cyclists with a fine risk similar to those of car drivers.

\section{RESULTS}

761 surveys $(95.3 \%)$ were eligible for statistical evaluation. Demographic characteristics are shown in Table $\mathbf{1 .}$

690 students reported going to the pub for a night out, on average 1.6 times per week. 445 of these students $(64.5 \%)$ reported traveling home by bicycle often or always. They reported drinking an average of 6.8 alcoholic drinks and their mean (SD) estimated BAC when traveling home was 0.95 $(0.9) \%$. 59 students reported having had a non-fatal bicycle accident during the past year. Characteristics for each BAC group are shown in Table 2 .

The percentage of accidents or injury for those who consumed no alcohol (BAC $=0 \%$ ) during the past year and reported traveling home by bicycle often or always was $2 \%$. Accident percentages differed significantly between the BAC groups $\left(\mathrm{F}_{5,439}=2.68, \mathrm{p}<0.021\right)$ are summarized in Table 2 . The overall odds ratio for alcohol drinking bicycle riders was 6.83 . Odds ratio of having a bicycle accident increased exponentially when having a higher BAC: $2.5(\mathrm{BAC}=0-0.2 \%), 6.8(\mathrm{BAC}=$ $0.2-0.5 \%), 6.0(\mathrm{BAC}=0.5-1.0 \%), 16.4(\mathrm{BAC}=1.0-1.5 \%)$ and 11.1 (BAC > 1.5\%). Logistic regression analysis revealed a significant $(\mathrm{p}<0.006)$ relationship between alcohol consumption and the risk of a bicycle accident.

The relationship between blood alcohol concentration and non-fatal bicycle accident risk is depicted in Fig. (1).

Students who travel home by bicycle report that there is a $41.9 \%$ chance that they will consume less alcohol on a night out when police controls for driving drunk are the same as for car drivers. This was not related to BAC levels.

\section{DISCUSSION}

Many people do not consider cycling when intoxicated as dangerous. Moreover, while they are aware that driving a car is not allowed after excessive alcohol consumption, they do not consider the consequences when riding a bicycle instead. Results from this survey show that bicycling when intoxicated implies great risks of accidents and related injury. This is of great concern, since the average bicyclist reported consuming numbers of alcoholic drinks that equaled a blood alcohol concentration corresponding to five-fold the legal limit for participating in traffic in The Netherlands $(0.02 \%$ for novice drivers $)$.

Causes of injury from bicycle accidents are multifactorial. Bicyclists often share the road with motorized traffic and they have relatively little protection while traveling at high speed. In addition, poor road conditions (e.g. holes or slippery roads) and weather circumstances (poor vision when driving at night or wind blasts) may have a greater impact on bicyclers when compared to car drivers.

\begin{tabular}{|c|c|c|c|}
\hline & Overall $(\mathrm{N}=\mathbf{7 6 1})$ & Men $(\mathrm{N}=213 ; 28 \%)$ & Women $(\mathrm{N}=\mathbf{5 4 8}, \mathbf{7 2} \%)$ \\
\hline Age (year) & $20.6(2.1)$ & $21.0(2.4)$ & $20.4(2.0)$ \\
\hline Length (m) & $1.74(0.09)$ & $1.84(0.08)$ & $1.71(0.07)$ \\
\hline Weight (kg) & $66.0(11.5)$ & $76.7(12.2)$ & $61.8(7.9)$ \\
\hline Drinking onset age & $13.8(1.6)$ & $13.5(1.9)$ & $13.9(1.5)$ \\
\hline Number of alcoholic drinks/week & $13.4(13.7)$ & $23.0(19.5)$ & $9.7(8.0)$ \\
\hline Drinking days/week & $3.4(1.9)$ & $4.3(2.0)$ & $3.1(1.6)$ \\
\hline Binge drinking days/week (>5 drinks) & $0.7(1.1)$ & $1.4(1.6)$ & $0.4(0.8)$ \\
\hline Number of nights out/week & $1.4(0.9)$ & $1.7(1.1)$ & $1.4(0.9)$ \\
\hline Number of drinks on a night out & $6.8(5.1)$ & $9.6(6.1)$ & $5.6(4.2)$ \\
\hline Estimated BAC when returning home & $0.95(0.9)$ & $1.0(0.9)$ & $0.9(0.9)$ \\
\hline
\end{tabular}

Making separate lanes for cyclists and protective clothing such as helmets have shown to significantly reduce the num-

Table 1. Demographics

Note: Standard deviations are shown between brackets. 
Table 2. Characteristics of Each BAC Group

\begin{tabular}{|c|c|c|c|c|c|c|}
\hline & $\mathbf{B A C}=\mathbf{0}$ & $0<$ BAC $<0.02$ & $0.02<\mathrm{BAC}<0.05$ & $0.05<\mathrm{BAC}<0.1$ & $0.1<\mathrm{BAC}<0.15$ & $\mathrm{BAC}>0.15$ \\
\hline Number $(\%)$ of students & $49(11.0 \%)$ & $42(9.4 \%)$ & $67(15.1 \%)$ & $122(27.4 \%)$ & $77(17.3 \%)$ & $88(19.8 \%)$ \\
\hline Age & $20.6(2.1)$ & $20.2(1.7)$ & $20.4(2.0)$ & $20.5(2.1)$ & $20.7(2.1)$ & $20.6(2.1)$ \\
\hline Drinking onset age & $14.3(2.0)$ & $14.3(1.3)$ & $14.1(1.5)$ & $13.7(1.6)$ & $13.6(1.5)$ & $13.4(1.7)$ \\
\hline $\begin{array}{l}\text { Number of alcoholic } \\
\text { drinks/week }\end{array}$ & $3.8(3.4)$ & $5.7(5.4)$ & $8.3(8.8)$ & $11.2(12.5)$ & $17.2(12.7)$ & $25.5(15.6)$ \\
\hline Drinking days/week & $2.1(1.3)$ & $2.7(1.6)$ & $2.9(1.7)$ & $3.4(1.8)$ & $4.2(1.9)$ & $4.3(1.8)$ \\
\hline $\begin{array}{l}\text { Binge drinking } \\
\text { days/week ( }>5 \text { drinks) }\end{array}$ & $0.04(0.2)$ & $0.1(0.5)$ & $0.2(0.7)$ & $0.5(1.0)$ & $1.1(1.2)$ & $1.8(1.4)$ \\
\hline $\begin{array}{l}\text { Number of nights } \\
\text { out/week }\end{array}$ & $1.1(0.6)$ & $1.2(0.7)$ & $1.4(0.7)$ & $1.6(0.9)$ & $1.8(0.9)$ & $2.2(0.8)$ \\
\hline $\begin{array}{l}\text { Number of drinks on a } \\
\text { night out }\end{array}$ & $1.0(1.4)$ & $3.3(2.0)$ & $4.1(1.6)$ & $6.0(2.3)$ & $8.1(2.2)$ & $14.4(5.1)$ \\
\hline $\begin{array}{l}\text { Percentage of bicycle } \\
\text { accidents }\end{array}$ & $2 \%$ & $4.8 \%$ & $13.2 \%$ & $10.7 \%$ & $24.4 \%$ & $18.2 \%$ \\
\hline
\end{tabular}

Note: Standard deviations are shown between brackets.

ber of injuries and accidents among sober cyclists, but in relation to alcohol use this may not be sufficient either since single-vehicle accidents are over-represented among alcohol intoxicated cyclists $[13,20,25]$. Compulsory helmet use significantly reduced the number of bicycle fatalities [26] and head and face injury [13]. Unfortunately, in many countries including The Netherlands there is no legislation on helmet use. Although it has been shown consistently that the use of bicycle helmets significantly reduce head and brain injury, intoxicated bicyclers significantly less often wear a helmet $[3,20]$. Education of bicyclists about the risk of cycling when intoxicated seems necessary. This is illustrated by the finding that about half of injured intoxicated bicyclists that reported at a Maryland hospital $(\mathrm{N}=120)$ had a history of alcohol-impaired car driving that resulted in license suspension, revocation or past convictions [27]. Prevention campaigns such as those focusing on drink driving for motorists should be targeted to cyclists as well and are essential to reduce the number of cycling accidents.

A limitation of this survey is that it presents retrospective data. The calculation of blood alcohol concentrations based upon reported number of drinks and drinking time results in a raw estimate. We tried to overcome these limitations by categorizing subjects into BAC-groups and calculate accident risks for these groups and not only on an individual basis as was done in the regression analysis. Although we believe that the results of this survey give a good impression that increased alcohol consumption goes hand in hand with increased bicycle accident risk, this should be verified by roadside surveys such as performed for car drivers. In this context, it would be necessary to set up a study as Borkenstein and colleagues (1964) did to examine the accident risk of car drivers in relationship to alcohol consumption [28]. His research team stopped several thousands of drivers, breath analyzed their alcohol level and after these subjects continued their journey the actual number of accidents they had were verified by police records. Adopting such an experimental approach will be necessary to confirm our survey findings. Future studies should have a larger sample size. It

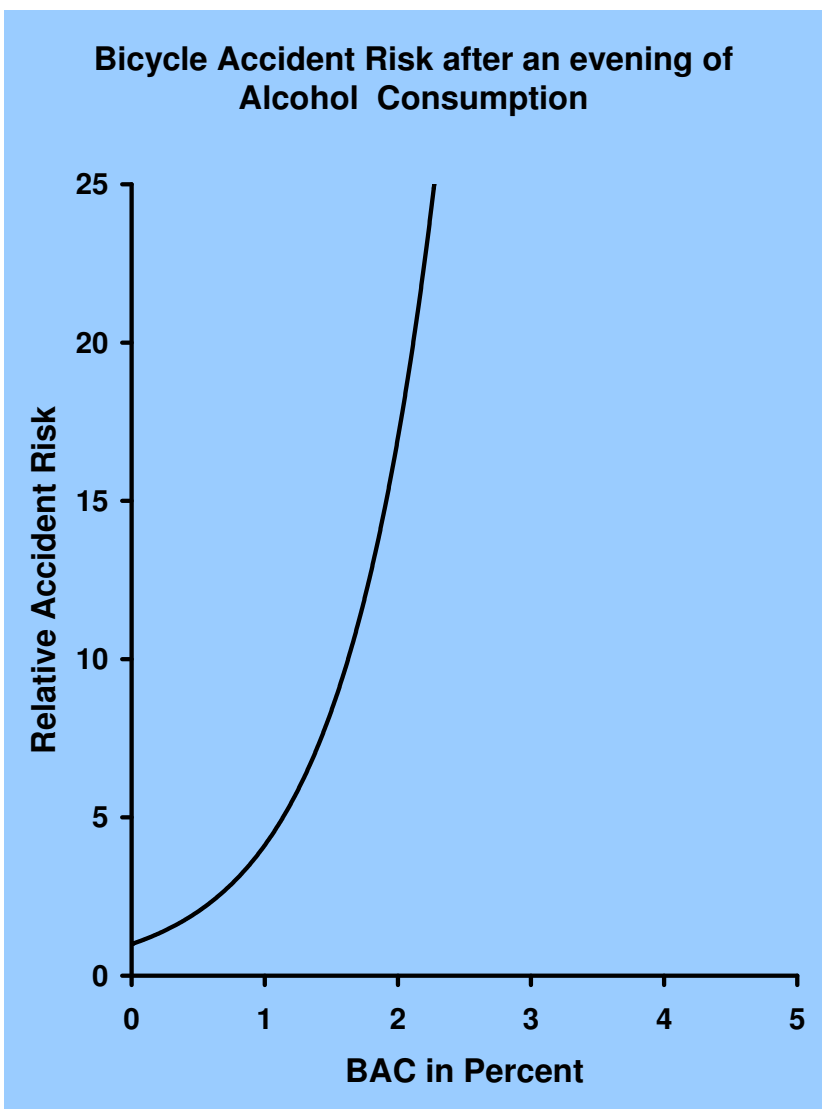

Fig. (1). The relationship between alcohol consumption and bicycle accident risk.

will then also be possible to differentiate between traffic accident types and whether accidents were with or without injury, or needed hospital treatment. It will then also be possible to determine the role of other factors like age, sex, and weight. Our sample size did not permit such analyses.

In conclusion, it is of great concern that students with blood alcohol concentrations that are five-fold higher than 
allowed to participate in traffic travel home by bicycle after an evening of alcohol consumption.

\section{REFERENCES}

[1] The Royal Society for Prevention of Accidents. Cycling accidents facts and figures, June 2005. [Accessed 2006 August 1]. Available from: http://www.rospa.co.uk.

[2] Center for Disease Control and Prevention. Injury control recommendations: bicycle helmets. MMWR CDC Surveill Summ 1995; 44(RR-1): 1-17.

[3] Spaite D, Criss E, Weist D, Valenzuela T, Judkins D, Meislin H. A prospective investigation of the impact of alcohol consumption on helmet use, injury severity, medical resource utilization and health care costs in bicycle-related trauma. J Trauma 1995; 38: 287-90.

[4] Dennerlein JT, Meeker JD. Occupational injuries among Boston bicycle messengers. Am J Ind Med 2002; 42: 519-25.

[5] SWOV- Factsheet. Fietsers. Leidschendam, December 2006. Accessible from: www.swov.n1/rapport/Factsheets/NL/Factsheet_Fiets ers.pdf

[6] BOVAG-RAI. Mobility in Figures. Two-wheelers 2008/2009. Amsterdam 2008. Available from: www.bovag-cijfers.nl/bovag_ci jfers_auto_nl_2008.html

[7] Bauman A, Rissel C, Garrard J, Ker I, Speidel R, Fishman E. Cycling: getting Australia moving: barriers, facilitators and interventions to get more Australian physically active through cycvling. Cycling Promotion Fund, Melbourne, 2008. Available from: http://www .cyclingpromotion.com.au/images/stories/downloads/C PFHlthRpr0 8V3prf1.pdf.

[8] Cooke CT, Marglius KA, Cadden GA. Cycling fatalities in Western Australia. Med J Aust 1993; 159: 783-5.

[9] Rowe BH, Rowe AM, Bota GW. Bicyclists and environmental factors associated with fatal bicycle-related trauma in Ontario. Can Med Assoc J 1995; 152: 45-53.

[10] Lutz FU, St. Kreidel H. Tödliche Zweiradunfälle - Ursachen, Verschulden. Z Rechtsmed 1988; 101: 1-8.

[11] Öström M, Björnstig U, Näslund K, Eriksson A. Pedal cycling fatalities in Northern Sweden. Int J Epidemiol 1993; 22: 483-8.

[12] Yelon JA, Harrigan N. Bicycle trauma: a five-year experience. Am Surg 1995; 61: 202-5.

[13] Andersson A-L, Bunketorp O. Cycling and alcohol. Injury 2002; 33: 467-71.
[14] Davidson JA. Epidemiology and outcome of bicycle injuries presenting to an emergency department in the United Kingdom. Eur J Emerg Med 2005; 12: 24-9.

[15] Schewe G, Knöss H-P, Ludwig O, Schäufele A, Schuster R. Experimental studies on the question of the marginal value of alcoholinduced unfitness to operate a vehicle in the case of bicyclists. Blutalkohol 1984; 21: 97-109.

[16] Li G, Baker SP, Smialek JE, Soderstrom CA. Use of alcohol as a risk factor for bicycle accidents. JAMA 2001; 285: 93-6.

[17] Kurzthaler I, Wambacher M, Golser K, et al. Alcohol and/or benzodiazepine use in injured road users. Hum Psychopharmacol Clin Exp 2003; 18: 361-7.

[18] Chiragra JF, Fife D, Conroy C. Incidence, severity, and outcomes of brain injuries involving bicycles. Am J Public Health 1987; 77: 76-8.

[19] Li G, Baker SP. Alcohol in fatally injured bicyclists. Accid Anal Prev 1994; 26: 543-8.

[20] Li G, Baker S, Sterling S, Smialek J, Dischinger P, Soderstrom C. A comparative analysis of alcohol in fatal and nonfatal bicycling injuries. Alcohol Clin Exp Res 1996; 9: 1553-9.

[21] Frank E, Frankel P, Mullins RJ, Taylor N. Injuries resulting from bicycle collisions. Acad Emerg Med 1995; 2: 200-203.

[22] Rosenkranz KM, Sheridan RL. Trauma to adult bicyclists: a growing problem in the urban environment. Injury Int J Care Injured 2003: 34: 825-9.

[23] Olkkonen S, Honkanen R. The role of alcohol in nonfatal bicycle accidents. Accid Anal Prev 1990; 22: 89-96.

[24] Watson PE, Watson ID, Batt RD. Prediction of blood alcohol concentrations in human subjects: updating the Widmark equation. J Stud Alcohol 1981; 42: 547-56.

[25] Delank K-W, Meldau P, Stol W. Die Traumatologie des Gesichtsschädels bei Farradünfallen. Laryngorhinootologie 1995; 74: 42831.

[26] Attewell RG, Glase K, McFadden M. Bicycle helmet efficacy: a meta-analysis. Accid Anal Prev 2001; 33: 345-52.

[27] Li G, Shahpar C, Soderstrom CA, Baker SP. Alcohol use in relation to driving records among injured bicyclists. Accid Anal Prev 2000; 32: 583-7.

[28] Borkenstein RF, Crowther RP, Shumate RP, Ziel HB, Zylman R. The role of the drinking driver in traffic accidents. Department of Police administration, Indiana University, Bloomington, Indiana, USA 1964.

(C) Verster et al.; Licensee Bentham Open.

This is an open access article licensed under the terms of the Creative Commons Attribution Non-Commercial License (http://creativecommons.org/licenses/by$\mathrm{nc} / 3.0 /$ ) which permits unrestricted, non-commercial use, distribution and reproduction in any medium, provided the work is properly cited. 